\title{
Les regards des Nord-Américains portés sur les cultures pueblo et navajo. Une histoire de cultures ou la culture de l'histoire?
}

Anglo-Americans' gaze on the Pueblos and Navajos cultures. A history of cultures or the culture of history?

\section{Estelle Brun}

\section{(2) OpenEdition}

1 Journals

\section{Édition électronique}

URL : http://journals.openedition.org/belgeo/11539

DOI : 10.4000/belgeo.11539

ISSN : 2294-9135

Éditeur :

National Committee of Geography of Belgium, Société Royale Belge de Géographie

\section{Édition imprimée}

Date de publication : 30 décembre 2013

ISSN : 1377-2368

Référence électronique

Estelle Brun, "Les regards des Nord-Américains portés sur les cultures pueblo et navajo. Une histoire de cultures ou la culture de l'histoire ? », Belgeo [En ligne], 3 | 2013, mis en ligne le 25 mai 2014, consulté le 22 mai 2020. URL : http://journals.openedition.org/belgeo/11539 ; DOI : https://doi.org/ 10.4000/belgeo. 11539

Ce document a été généré automatiquement le 22 mai 2020.

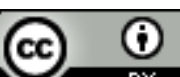

Belgeo est mis à disposition selon les termes de la licence Creative Commons Attribution 4.0 International. 


\title{
Les regards des Nord-Américains portés sur les cultures pueblo et navajo. Une histoire de cultures ou la culture de l'histoire?
}

\author{
Anglo-Americans' gaze on the Pueblos and Navajos cultures. A history of \\ cultures or the culture of history?
}

Estelle Brun

Je tiens à remercier Maria Gravari-Barbas, Professeure de Géographie à Paris PanthéonSorbonne et Nelson Graburn, Professeur d'Anthropologie à UC Berkeley ainsi que leur Tourism Studies Working Group pour leur lecture et commentaires sur mon travail.

1 La notion de "tourisme culturel », utilisée depuis les années 40 par les institutions internationales telles que la Banque Mondiale, l'Organisation Mondiale du Tourisme (OMT), l'UNESCO ou même l'ICOMOS (Conseil International des Monuments et des Sites), est née de la volonté de sauvegarder le patrimoine et d'apporter des devises pour les pays en voie de développement (Krapf, 1961; Unesco, 1966; Robinson et Picard, 2006, cités dans Cousin, Martineau, 2009). «Le tourisme culturel est né avec la doctrine du progrès, il est devenu un enjeu des théories du développement, il s'est nourri de la transformation du sens et des valeurs associées aux notions de culture et de patrimoine » (Cousin, 2008). La «doctrine du tourisme culturel» (Picard, 1992, cité dans Cousin, 2008) «reste centrée sur l'idée que le tourisme serait un phénomène apolitique, vecteur d'échanges culturels et de recettes économiques». Pourtant, les enquêtes ethnographiques qui se multiplient à travers le monde "révèlent que le tourisme culturel est au centre d'enjeux politiques et de rapports de pouvoirs de toutes sortes et de toutes échelles » (Cousin, Martineau, 2009).

2 Par leur inscription au Patrimoine Mondial culturel, les sites de la culture Chaco (Chaco Cañon et Aztec Ruins), de Mesa Verde et de Taos Pueblos ${ }^{1}\left(\mathrm{~V}^{\mathrm{e}}-\mathrm{XIV}^{\mathrm{e}} \mathrm{s} \text {. }\right)^{2}$ s'inscrivent dans $^{2}$ ce contexte, exposés à l'échelle mondiale par ce label international. Leur ajout sur la 
liste du patrimoine de l'UNESCO en tant que biens culturels est d'autant plus notoire que l'ensemble des États-Unis n'en regroupe que neuf, dont un mixte, en 2013. Ils peuvent donc être considérés comme les représentants de la culture amérindienne aux États-Unis, symbole d'autant plus fort que ces sites ont la particularité d'être rattachés à une « culture vivante »; en effet, selon ces tribus, ils sont les témoins de la culture des Navajos et des Indiens Pueblos, anciennement nommés Anasazis ${ }^{3}$, peuple amérindien du Grand sud-ouest américain dont le passé remonte à l'époque précolombienne et qui a survécu jusqu'à présent. Ces sites illustrent les anciennes traditions culturelles de ces tribus amérindiennes et permettent de faire le lien entre les modes de vie passé et présent de ces dernières qui n'ont eu de cesse de vouloir perpétuer leurs coutumes ancestrales jusqu'à aujourd'hui ; ils ont ainsi gardé mémoire de ces lieux imprégnés de la présence de leurs ancêtres à travers leurs traditions orales, sous la forme de chants et de prières. À ce titre, par l'application de la loi NAGPRA ${ }^{4}$, ces patrimoines, classés aussi en tant que Parcs Nationaux, à l'exception de Taos Pueblo, ont par conséquent été officiellement affiliés à des tribus actuelles, parmi les Pueblos et Navajos ${ }^{5}$ vivant dans la région des Four-Corners (Utah, Colorado, Nouveau-Mexique et Arizona); ainsi, le Gouvernement Fédéral, les reconnaissant comme les descendantes des Ancêtres Pueblos, leur accorde un rôle de consultants dans la gestion de ces sites.

3 Ces territoires, habités par des populations qui ne se sont que peu déplacées depuis plus d'un millénaire, dont les vestiges et traditions légitiment leur appartenance à ces régions, sont donc animés de multiples enjeux qui s'étendent bien au-delà du simple phénomène économique auquel le tourisme est toujours associé. Aborder les regards des Nord-Américains portés sur la culture pueblo et navajo a ainsi pour but de mettre en relief les multiples dimensions de cette mise en patrimoine, autant à l'échelle locale que nationale ou mondiale. Dans le contexte actuel de la mondialisation, il semblerait que l'évolution des regards associés au patrimonial amérindien soit accompagnée d'une évolution des relations interculturelles sur le territoire patrimonial étendu. Cette étude se concentrera sur différents acteurs tels que les Euro-Américains, touristes ou professionnels, associés à ces sites patrimoniaux, mais aussi sur les Amérindiens pueblos et navajos et le regard qu'ils portent sur le patrimoine en général mais surtout sur le leur. Par là même, il s'agira de comprendre en quoi le patrimoine et les imaginaires qui lui sont associés peuvent interférer sur une culture, en permettant ou non sa revitalisation culturelle.

4 La question même du "regard " a déjà été abordée dans le contexte patrimonial ; la sociologue Nathalie Heinich, par exemple, l'a fait en favorisant l'approche esthétisante de l'objet. Dans mon cas d'étude, j'ai fait le choix de me centrer sur cette notion dans un sens plus large, afin de mettre en avant qu'il n'existe non pas un unique regard mais une multitude de regards portés sur ces cultures minoritaires, sur les territoires patrimoniaux et plus largement dans ces états.

5 Par le «regard», mon analyse jongle entre imaginaires et représentations patrimoniales par une démarche compréhensive et une investigation des pratiques, afin non pas de mettre en évidence les différences ou ressemblances entre acteurs ou catégories mais plutôt afin de comprendre comment ces territoires sont mis en patrimoine et ces cultures exposées; il s'agit là de mettre en avant les différents acteurs qui ont leur propre rôle à jouer et d'exposer leurs perceptions et réflexivités.

6 Dans une première partie sont abordés les regards extérieurs à cette culture, c'est-àdire les perceptions exposées par les Euro-Américains sur ces populations à travers 
l'étude de ces patrimoines. Au-delà de l'accessibilité physique à un lieu, son appropriation symbolique, ses imaginaires, jouent un rôle tout aussi important. Comme l'a si bien résumé J. Urry, ce n'est pas seulement les touristes qui voyagent «mais aussi les objets, les cultures et les images » (Urry, 2001). D'un point de vue national, la "production architecturale, mais aussi la patrimonialisation d'édifices hérités, sont des vecteurs très importants d'affirmation symbolique de groupes sociaux et de pouvoirs institutionnalisés »; ils sont les vecteurs d'une "appropriation symbolique » ou « identitaire » (Veschambre, 2005). Dans le cas précis des Pueblos et Navajos, la mise en tourisme de ces patrimoines offre l'opportunité de briser certains imaginaires persistants, de «réécrire" l'histoire connue (voire méconnue), véhiculée dans les écoles américaines; mais surtout, elle permet de redonner à chacun de ces peuples une « existence » à part entière; en effet, malgré leur passé commun sur certains de ces sites culturels, les Ancêtres Pueblos ont fini par se disperser autour des XIII ${ }^{\text {ème }}$ et XIV ${ }^{\text {ème }}$ siècles, de manière privilégiée le long du Rio Grande; chaque groupe s'est ainsi peu à peu distingué culturellement, par le développement d'une langue unique et par l'application de coutumes propres à chacun.

7 Ce « voyage virtuel » est ensuite mis en relief par le « voyage corporel » afin d'aborder les différents regards touristiques, c'est-à-dire les différents types de visiteurs, avisés ou amateurs, qui, nous le verrons, ont un rapport direct avec le type d'accessibilité à ces sites ; Chaco, étant géographiquement très isolé, intéresse un public bien différent de celui de Mesa Verde, beaucoup plus simple d'accès, et donc ouvert à un public national et international bien plus nombreux, mais en général moins connaisseur des cultures représentées par ce patrimoine. Une parenthèse est faite sur le terme de «spécialiste », terme peu apprécié par les populations amérindiennes qui y voient une certaine prétention des «Blancs » à vouloir contrôler les informations divulguées sur leur culture, informations qui échappent de plus à leur contrôle. Il est en effet important pour eux de rendre le dialogue culturel autour de leurs cultures aussi fidèle que possible; ainsi, la fin de cette partie met en relief l'évolution des regards des « spécialistes » selon la culture occidentale (archéologues, sociologues et historiens), et plus généralement celui du Gouvernement Fédéral, portés sur le savoir culturel des descendants de ces sites, notamment depuis les années 1990 ; les savoirs ancestraux des héritiers de la culture ancestrale pueblo sont désormais reconnus et valorisés.

8 La deuxième partie de cette étude expose les regards amérindiens (pueblos et navajos) portés sur leur propre patrimoine et les enjeux qui découlent des affiliations culturelles : du côté du Gouvernement Fédéral, ils n'hésitent pas à leur rappeler qu'ils doivent «réparer» le passé, par la restitution de terres et la possibilité d'une collaboration proche concernant la gestion des patrimoines auxquels ils sont culturellement affiliés. Du côté des tribus uniquement, ces enjeux demeurent, encore plus forts lorsqu'ils sont proches de leurs lieux d'habitation et relatifs aux ressources; l'accès à l'eau reste celui le plus disputé. Ainsi, ils n'hésitent pas à utiliser comme moyen le prétexte de l'«affiliation culturelle » à certaines terres et aux «ruines " qu'elles abritent, afin de légitimer leur demande de restitution de terre, souvent à l'encontre d'une autre tribu voisine.

9 D'un point de vue patrimonial, leur influence se fait davantage ressentir sur les patrimoines proches de leur lieu de vie, patrimoines historiquement plus proches et dont les traditions orales rapportent des souvenirs précis; à l'inverse, les sites plus anciens comme Chaco semblent provoquer de nombreuses « spéculations » sur la cause 
de leur existence. Ce savoir est en effet loin d'être un savoir commun à l'ensemble de ces communautés; réduites à l'échelle de clans, les traditions orales sont le plus souvent ignorées des autres clans, au sein d'un même village.

Enfin, la mise en parallèle de gestions différentes sur des sites d'époques similaires (exemple de Mesa Verde/Ute Mountain Park) et les propos récoltés lors de réunions tribales permettent de mettre en évidence l'existence d'un regard amérindien patrimonial différent de la vision euro-américaine focalisée sur la préservation des vestiges, " coûte que coûte ». Cependant, la perte de transmission des savoirs de façon traditionnelle entraîne aujourd'hui un changement d'orientation du regard amérindien, désormais divisé entre l'application de leurs traditions culturelles et l'influence d'une vision étrangère, celle des Euro-Américains, qui affecte de plus en plus les jeunes générations de Pueblos et Navajos.

11 Cet article résulte essentiellement d'un travail personnel, associant études d'archives (notamment d'enquêtes touristiques réalisées dans les parcs), observation participante chez les Pueblos et dans les parcs en tant que volontaire pour le National Park Service, et entretiens semi-directifs et qualitatifs auprès de touristes, de membres tribaux affiliés à ces sites ainsi qu'auprès des équipes de gestion de chacun des parcs. Deux limites sont à noter cependant, d'une part l'interdiction d'interviewer «officiellement » les touristes ${ }^{6}$ - il a donc fallu que je mène des entretiens au fil d'une conversation-, d'autre part l'impossibilité d'enregistrer la majorité des Amérindiens, par respect pour leurs croyances ${ }^{7}$.

12 Afin d'affiner au mieux un travail de comparaison, le terrain a été élargi afin d'inclure d'autres sites patrimoniaux gérés par différents organismes, parmi les parcs (Canyon de Chelly, Puye Cliff, Bandelier...) et les musées (Museum of Indian Art and Culture, Santa $\mathrm{Fe}$; Anasazi Center, Dolores...). Ces études se sont déroulées en deux étapes, durant l'automne 2012 et l'été 2013.

\section{Le regard, une source d'émotion, une source critique?}

13 C'est bien par le regard que Stendhal, au paroxysme de l'émotion, a failli perdre connaissance; ainsi, en 1817, il nous conte dans ses carnets de voyage son séjour à Florence et l'événement, aujourd'hui connu sous le nom de "syndrome de Stendhal » :

"J'étais dans une sorte d'extase, par l'idée d'être à Florence, et le voisinage des grands hommes dont je venais de voir les tombeaux. Absorbé dans la contemplation de la beauté sublime, je la voyais de près, je la touchais pour ainsi dire. J'étais arrivé à ce point d'émotion où se rencontrent les sensations célestes données par les beaux arts et les sentiments passionnés. En sortant de Santa Croce, j'avais un battement de cœur, la vie était épuisée chez moi, je marchais avec la crainte de tomber.»

(Stendhal, 1817).

14 Aussi, le regard, critique, admiratif, expressif, contemplatif, dubitatif, vif, songeur, soutenu... revêt de multiples facettes. Individuel ou collectif, affronté ou échangé, mais rarement neutre, le regard induit une «relation avec l'autre, consciente ou inconsciente, directe ou indirecte, intentionnelle ou spontanée, et sa portée est rarement dépourvue de conséquences. Il peut ainsi revêtir, à bon ou mauvais escient, le sens de jugement, se faire inquisiteur, réprobateur, culpabilisateur [...] compassionnel 
ou indulgent»(Pichouron, 2010; Heinich, 2009). Il peut également prendre des connotations morales.

Considéré comme un auxiliaire de l'apprentissage et de l'ouverture d'esprit, il apparait comme un remède efficace à l'ignorance, «en nous ouvrant sur le monde et en permettant l'accès à la connaissance » (ibid.). Le regard modifie alors l'expérience et arrive parfois à jouer un rôle conséquent dans l'acceptation de la différence.

Dans le contexte patrimonial et selon la seule dimension matérielle, le regard amène à la production d'un savoir «sur ce qui est à voir» (Heinich, 2010, p. 166). Le regard de l'expert, archéologue, anthropologue, architecte, historien..., ainsi que le regard individuel porté sur l'objet patrimonial et relayé par les médias, propose alors au plus grand nombre, dans une logique de sensibilisation, de transmission et de marquage, une prise de conscience et une appropriation collective de la valeur symbolique de l'objet. Les sites du Patrimoine Mondial sont ainsi marqués comme les lieux culturels "à faire ». Ne serait-ce que la démarche de classer un site sur la liste de patrimoines culturels mondiaux peut éveiller un regard critique à l'encontre de l'Unesco, entre autres. Bien que celle-ci prône des valeurs censées être devenues universelles, il peut se heurter, malgré tout, aux valeurs patrimoniales de cultures minoritaires qui ne se reconnaissent pas dans ces valeurs universalisées qu'elles ressentent même comme des valeurs occidentalisées.

Quels sont donc ces regards et représentations culturelles associés au patrimoine amérindien?

\section{Un regard uniforme, nourri par des imaginaires}

\section{Le contexte socio-culturel et historique}

Cette partie du pays, couvrant aujourd'hui les États du Nouveau-Mexique, Colorado, Utah, Arizona, Nevada et le sud de la Californie, se distingue historiquement et culturellement pour avoir été sous influence espagnole puis mexicaine jusqu'en 1845-48, date à laquelle le Mexique perd la guerre américano-mexicaine et par là, les terres du sud-ouest américain (Pérez, 2011); toutefois, ces régions, mais surtout le Nouveau-Mexique, sont encore fortement marquées par ces deux cultures, hispanique et amérindienne, mixité dont la ville de Taos est un parfait exemple. La dénomination même de "Pueblos", qui a survécu jusqu'à nos jours, fait aussi référence à cette colonisation au cours de laquelle les Espagnols ont ainsi nommé des habitants sans distinction aucune de leur appartenance, leur attribuant ainsi le nom de «pueblos » ou "villages ». Ce nom, uniformisateur à défaut, regroupe cependant différentes tribus dont chacune a sa propre langue, les plus célèbres étant celles des Hopis et des Zunis. Cette tendance encore à mettre indifféremment ensemble tous les groupes socioculturels amérindiens sous la dénomination commune d'«Indiens" témoigne du regard uniforme porté sur ces civilisations. À noter, il a été choisi de favoriser ici le terme d'" Amérindien ", évitant ainsi la confusion avec les Indiens d'Asie; de plus, ce terme, préféré des Canadiens - les Français utilisant plutôt «Indien d'Amérique » -, souligne, selon moi, la dualité de cultures de ces populations, à la fois indiennes et américaines. Comme le remarque aussi Anne Garrait-Bourrier, les peuples concernés, eux, n'optent pour aucune de ces désignations étrangères, désirant être appelés par leur nom tribal (Garrait-Bourrier, Vénuat, 2002). 
19 À l'époque de la colonisation, «l'Indien est celui qu'il fallait repousser toujours plus loin pour pouvoir « civiliser » l'espace qu'il habitait, en le parquant dans des réserves avec drogue et alcool puisqu'il ne voulait pas perdre son identité culturelle » (GarraitBourrier, Vénuat, 2002); ce sont des clichés qui aujourd'hui encore nourrissent les imaginaires attachés à ces populations, aussi bien aux Etats-Unis qu'en Europe, dont les images ont été largement véhiculées par le $7^{\text {ème }}$ Art : l'Indien du temps des Westerns, vivant dans des plaines, sous un tipi, ou cloisonné dans des réserves. Constance Classen décrit ainsi ce phénomène : «la culture moderne occidentale est une culture des yeux. Nous sommes constamment bombardés, séduits et définis par des modèles et représentations visuelles, des cartes aux graphiques, en passant par les images et les textes" (Classen, 1998). Ce processus est accentué par le phénomène de la mondialisation; par l'apparition des téléphones mobiles, d'internet..., nous assistons à « une production omnivore et à la consommation de l'espace par des images et des sons à distance " (Urry, 2002). Le tourisme est donc devenu un phénomène mondial, soutenant le fait que les cultures sont commercialisées, créant et recréant la production d'images de l' « Autre » (ibid.).

20 Ces temps révolus restent une grande source d'inspiration pour de nombreux artistes de la région et de l'Ouest Américain; les galeries d'Art, dans le Vieux Scottsdale par exemple (Phoenix, Arizona) foisonnent de tableaux et sculptures représentant les Indiens des Plaines, à cheval ou non, peu vêtus si ce n'est de quelques peaux et de plumes en guise de parures, tels de braves guerriers, fiers défenseurs de leurs valeurs culturelles. Ces œuvres sont un témoignage flagrant de l'évolution du regard des EuroAméricains porté aujourd'hui sur ces peuples autrefois dénigrés, même si l'image du «noble guerrier " apparaît dès le XIX ${ }^{\text {ème }}$ siècle (Garrait-Bourrier, Vénuat, 2002), avec une place de choix dans The Last of the Mohican (James Fenimore Cooper, 1826, cité dans Garrait-Bourrier, Vénuat, 2002). Les photographies « authentiques » d'Edward S. Curtis (1868-1952)', largement diffusées dans les années 1970-80, seront également l'un des principaux véhiculeurs d'imaginaires en Amérique et en Europe.

21 Jd Challenger, installé à Taos, illustre parfaitement ces artistes euro-américains contemporains dont la culture amérindienne a su nourrir l'essentiel de leur inspiration; ainsi, ses peintures entrelacent symboles du passé et du présent, tentant de reproduire l'essence amérindienne, découverte grâce à son amitié avec des membres tribaux ; c'est d'un sage amérindien qu'il reçut l'approbation de partager ses œuvres et de se positionner en tant que "messager» de leur situation: "ton destin est de raconter notre histoire et d'informer les gens sur notre passé et sur ce qui se passe encore aujourd'hui» (int. Jd Challenger, 25/10/12). Ces imaginaires sont ainsi constamment retransmis et réadaptés, témoignages d'une nostalgie liée à la perte de l' " authentique ». On voit bien que les artistes ont, pour leur part, grandement contribué à divulguer ce regard uniforme, inchangé qu'a le monde sur ces populations.

Le patrimoine affilié à ces cultures joue-t-il un rôle sur la question? Très probablement, comme nous le verrons plus tard. Mais il reste important de souligner que ces imaginaires sont réemployés par les Amérindiens eux-mêmes ; il n'est pas rare de voir en bord de route, associée à une boutique navajo, la reproduction d'un tipi ou d'un hogan traditionnel ${ }^{10}$. D'un autre côté, certains Pueblos dénigrent fortement ces imaginaires associés aux "Amérindiens ", résultant d'un manque de culture ${ }^{11}$ et de la propagande autour des Westerns et des Indiens des Plaines, prônant le fait que leurs cultures sont très différentes et que chaque peuple, même au sein des Pueblos, présente 
ses propres particularités (int. J. Aragon, Acoma, 09/13; int. Bryan, San Idelfonso Pueblo, 09/13 ; int. B. Chavarria, Santa Clara Pueblo, 09/13). Il est important pour eux d'être perçus différemment et d'avoir une existence à part entière en tant que groupe culturel.

Aujourd'hui, les Indiens sont également des citoyens américains ${ }^{12}$, de plus en plus «intégrés à la population urbaine et fondus dans les diverses classes sociales existantes» (Garrait-Bourrier, Vénuat, 2002); mais il subsiste encore des luttes politiques, territoriales et culturelles autour de ce que les Américains continuent d'appeler « la question indienne $»^{13}$.

\section{Le regard d'une nation sur ce patrimoine} d'arguments touristiques afin de répondre aux attentes des touristes, fait universellement observé. La plupart des boutiques touristiques présentent un mélange d'arts navajo, pueblo... et même mexicain, regroupés sous la même dénomination d'art « natif », sans nécessairement en indiquer la provenance. Les Amérindiens ont toutefois défendu ce qu'il conviendrait d'appeler la "marque amérindienne »; il est désormais interdit pour un non-Amérindien de reproduire des arts amérindiens à des fins commerciales. issus de la culture des Ojibwés, peuple ancré au Canada et au Nord des États-Unis, ne surprend pourtant personne. Ces marqueurs de la culture amérindienne, mis à la disposition du regard touristique, fortifient de fait une unicité culturelle à l'échelle du «peuple amérindien" qui n'a pas lieu d'être. A l'inverse, les sites patrimoniaux, témoins de cultures amérindiennes diverses, révèlent la spécificité de groupes ethniques, permettant de redonner une valeur culturelle à chacun de ces peuples individuellement.

Amérindiens comme des minorités ethniques auxquelles il est nécessaire d'apporter un soutien, les témoignages architecturaux en pierre subsistants évoquent une civilisation florissante dont ils n'avaient pour l'ensemble pas connaissance et qui les surprend positivement à plus d'un égard (int. C. Swanborg, Phoenix, 11/12). Ils le reconnaissent tous, l'histoire amérindienne, à l'école et au lycée, n'est abordée que dans le contexte de l'arrivée des «Blancs» (int. touriste Aztec Ruins-26, 26/07/13 par exemple); pourtant, c'est par la découverte du passé que les Pueblos et Navajos peuvent connaître une revalorisation culturelle, en laissant les visiteurs découvrir ou redécouvrir «proprement » leur culture à travers leur patrimoine; par conséquent, ils soutiennent ce tourisme mais « surtout, c'est important pour eux que les véritables histoires soient racontées » (int. L. Turk, Surintendant de Chaco et Aztec Ruins, 10/12). C'est pour cela qu'ils veulent consulter le National Park Service, pour s'assurer qu'ils ont «bien les bonnes informations » (ibid.).

Dans ce contexte, le patrimoine joue un rôle éducatif très important en ce qui concerne ces cultures dont la plupart des visiteurs ignorent beaucoup, ne serait-ce que le fait que la culture des Ancêtres Pueblos n'a pas disparu mais se distingue encore aujourd'hui, notamment à travers les Pueblos actuels. Mesa Verde semble regrouper une grande majorité de ces visiteurs qui viennent là sans rien savoir au préalable, pour «faire un 
Parc National»; souvent, cette visite n'inclut pas d'autres sites d'Ancêtres Pueblos, mais plutôt celles de grands Parcs Nationaux comme Yellowstone, Bryce Canyon et le Grand Canyon. Aztec Ruins, sur la route de Mesa Verde, est couramment un arrêt imprévu et regroupe une concentration de touristes aux motivations similaires. Par contre, Chaco Cañon, site reculé avec pour seul accès un chemin de terre (voir travaux de R. Shieldhouse sur le sujet), requiert une véritable démarche préalable et une certaine motivation; pour cette raison, ce site attire un nombre exceptionnel de touristes pré-connaisseurs des cultures pueblos et navajo, qui viennent et reviennent ${ }^{14}$ pour l'exceptionnalité du lieu, recherché de par son histoire et une beauté surprenante et sauvage, à l'écart de la civilisation. Le plus souvent, ce sont ces connaisseurs qui répondront non favorables à un projet de construction de route goudronnée (Int. touriste Chaco-15. 07/08/13, int. tour. C-22. 09/08/13, int. tour. C-25. 09/08/13, int. tour. C-30. 10/08/13, int. tour. C-35. 10/08/13...) car cet isolement permet de sélectionner d'une part, le nombre de touristes - offrant donc une expérience de qualité -, d'autre part, le type même de touristes assimilés par leurs intentions à des « experts ». Cette route en terre permet ainsi une « sélection naturelle» d'un touriste " éduqué » par la lecture de livres archéologiques et par la visite de nombres autres sites de la même période, Bandelier, Hovenwip, Canyon de Chelly.... Cependant, le visiteur euro-américain visite l'ensemble de ces sites avec une approche archéologique, dans le sens où la connexion avec les populations actuelles n'est que rarement ressentie ${ }^{15}$.

De plus, les Pueblos sont quasi-inexistants sur la scène touristique, ne possédant pas d'hôtels, restaurants ou autres structures touristiques près de ces sites ou dans les villes les plus proches (Cortez, Durango, Farmington); dans ce contexte, sachant que moins d' $1 \%$ des touristes de Mesa Verde se rend dans des Pueblos, très rares sont les lieux de rencontre et d'échange entre Euro-Américains et Amérindiens (int. Chr. Dutie, Office de tourisme d'Aztec, $10 / 12^{16}$ ) si ce n'est dans quelques boutiques navajos et dans les villages d'Acoma et Taos notamment; la plupart restent au final plutôt concentrés dans leurs réserves, entre membres de leur tribu. Même s'ils vivent des expériences universitaires, militaires ou professionnelles en dehors de leur village, ils finissent souvent par désirer un "retour aux sources", parmi les leurs; au-delà d'un fort attachement à la terre, il s'agit aussi d'un mode de vie auquel ils tiennent particulièrement: "quand vous grandissez parmi ce cercle traditionnel qui affecte votre vie quotidienne, c'est seulement quelque chose que vous pouvez trouver au village » et nulle part ailleurs (int. R. Suazo, Taos Pueblo, 09/13).

L'ouverture de ces patrimoines au public, témoins de leur présence passée sur ces terres, peut donc encourager un changement de regards sur les populations amérindiennes actuelles. Cependant, les rangers et les conservateurs du patrimoine concentrent leur discours sur la façon dont vivaient ces populations dans ces lieux du passé, et non sur la façon dont leurs descendants le font aujourd'hui ; "c'est un changement dans le service des Parcs \{Nationaux\}, surtout ici où il y a des descendants; c'est eux qui doivent parler d'eux-mêmes et non pas à nous de parler pour eux, ou du moins, nous ne devrions pas le faire! Mais nous pouvons parler de la façon dont nous connaissons l'Histoire \{d'il y a 1000 ans\} [...], grâce à l'archéologie, la science » (int. D. Ford, Chef des Ressources Culturelles de Chaco, 10/12).

30 Enfin, ces patrimoines sont, dans l'ensemble, plutôt connus localement, dans leur département, notamment Chaco et Taos (ibid.). Mesa Verde est, par contre, à plus 
grande échelle, une attraction nationale et mondiale, visitée surtout pour son environnement naturel et la particularité des Cliffs-Dwellings (habitats troglodytes). De la même façon, l'histoire de ces cultures est de plus en plus incluse dans les programmes historiques des écoles locales, du Nouveau-Mexique et du Colorado, qui centrent leur choix sur l'apprentissage de l'histoire régionale ; ce choix est soutenu par la promotion de programmes éducatifs réalisés directement par les équipes du National Park Service, surtout à Chaco et Aztec Ruins. Selon Carol Sperling, chef de l'équipe d'interprétation de Mesa Verde, ce site est encore relativement inactif dans ce domaine et ne soutient pas assez la promotion de ces sites auprès des écoles (int. Carol Sperling, 09/13, Mesa Verde).

\section{Un regard averti, celui des « spécialistes " sur le territoire}

31 Selon la vision euro-américaine, un « spécialiste » est une personne dotée d'un diplôme ou autre titre reconnu nationalement dans un domaine particulier pour avoir travaillé de manière approfondie sur un sujet donné. Ainsi, un anthropologue qui a suivi une formation sur les populations du sud-ouest américain est considéré comme « spécialiste » de ces dernières. Ce poids accordé à la parole de tels «spécialistes » reste en général très critiqué par les populations issues de ces cultures, qui soutiennent être les seuls véritables connaisseurs de leur propre culture (interviews diverses). Ce point a provoqué l'essentiel des reproches du côté des représentants amérindiens lors de la réunion tribale qui s'est déroulée entre le National Park Service et les tribus affiliées (Aztec, juillet 2013) ; ainsi, Stan Bond, archéologue "spécialiste ", a été envoyé par le bureau de Washington DC afin de présenter certains articles de loi associés au programme NAGPRA, portant notamment sur le stockage et la restitution des « objets archéologiques ». Son discours, centré sur le travail des archéologues "spécialistes de ces populations ", alors que ceux-ci classaient tous les objets de la même façon sans prendre en compte la valeur portée aux objets sacrés et funéraires par les représentants amérindiens, a provoqué bien des émois parmi les descendants des Ancêtres Pueblos qui n'ont pas manqué de rappeler qu'eux seuls étaient les véritables «spécialistes » de leur culture, et non une personne dotée d'un diplôme. Par contre, les responsables d'Aztec Ruins, eux habitués à travailler avec les Amérindiens depuis des années, n'ont absolument pas été surpris de ces réactions après un tel discours (int. L. Turk, Aztec, 07/13).

32 Cet exemple parmi d'autres illustre clairement que l'exposition à un contact permanent avec les populations natives de ces territoires a modelé et enrichi le regard porté sur ces dernières ; agents du National Park Service, anthropologues, archéologues... évoluent dans leur façon d'appréhender ce patrimoine et ces cultures. Plus au fait des traditions et de la culture de ces derniers, la majorité des employés en ressources culturelles et touristiques des sites montre non seulement un grand respect mais aussi une forte curiosité intellectuelle; parmi les équipes permanentes ou résidents à long terme, nombreux sont ceux qui sont allés voir les Pueblos durant leur fête annuelle, fête à laquelle tout public est invité. Leur investissement passe par la rencontre avec les descendants de ces populations, rencontres aussi organisées au sein des parcs ${ }^{17}$, ainsi que par la lecture de livres recommandés par le National Park Service. Ce changement d'orientation du discours, ce dernier devenant plus "humanisé», est notoire 
essentiellement à partir de 1990. Ils acquièrent ainsi un double discours, l'un basé sur les découvertes archéologiques, l'autre sur les "voix amérindiennes"; de nombreux rangers, quand certains éléments architecturaux restent incompris et divisent l'avis des archéologues, n'hésitent pas à signaler qu'ils accordent plus de valeur aux explications offertes par les Amérindiens du fait de cette transmission générationnelle de savoirs depuis des siècles (tour guidé du Teacher-ranger K. Dunlap, Aztec Ruins, 07/13).

33 A Mesa Verde, les «anciens » de l'équipe n'hésitent pas à consulter l'unique guide navajo afin d'ajuster leur discours et de l'humaniser (int. Cl. Benally, Navajo Nation, 09/13). Le poids de ce savoir amérindien est soutenu par le fait que leurs cultures actuelles présentent beaucoup de similitudes avec cette ancienne civilisation; d'un point de vue architectural, par exemple, la survivance des kivas ${ }^{18}$ circulaires depuis l'époque des Ancêtres Pueblos jusqu'à aujourd'hui en reste une preuve incontournable ${ }^{19}$ ; de la même façon, certains objets sacrés ou de la vie courante retrouvés parmi ces sites anciens sont encore utilisés par les populations actuelles lors de cérémonies privées ou révèlent des souvenirs d'enfance, certains revoyant comment leurs grandsparents utilisaient certains de ces objets.

La réunion d'Aztec fut également intéressante à ce sujet ; archéologues et Amérindiens furent placés dans une même pièce afin de présenter certains objets disponibles pour un rapatriement. Les étiquettes archéologiques aux descriptions indécises, « hachette », «bâton décoré »..., furent rapidement évincées par les récits précis et imagés contés par les Pueblos et Navajos présents. Chaque objet a alors pris un sens, employé pour des activités quotidiennes ou, en fonction de son matériau, de la finesse de son exécution et de la présence de certains symboles, attribués à l'ordre du sacré ; cette distinction, difficile à faire, sans cet échange, pour un archéologue, est apparue alors facilement réalisable grâce aux descendants des Ancêtres Pueblos qui se sont succédés les uns après les autres dans cette salle et ont tous attribué à ces objets des fonctions relativement similaires dans l'ensemble. Il ne s'agit pas, tant s'en faut, de dénigrer le travail des archéologues mais au contraire de mettre l'accent sur cette revitalisation culturelle provoquée, grâce à eux, par un regain d'intérêt porté au savoir de ces peuples, éveillant chez ceux-ci l'importance que peut avoir leur passé; il est aussi question de souligner l'utilité de cette interaction afin que soient affinées au mieux la pertinence et la justesse du discours scientifique porté sur ces populations, discours essentiellement véhiculé par les rangers des Parcs Nationaux. Ce n'est d'ailleurs pas la première fois qu'un travail anthropologique est accompli afin d'apporter des réponses à des interrogations jusque-là non résolues. Cet échange montre aussi à quel point il est à l'heure actuelle important pour le National Park Service, d'autant plus dans l'État du Nouveau-Mexique peuplé de minorités majoritaires ${ }^{20}$, de développer un dialogue avec les populations natives de ces territoires, dialogue souvent élidé ou absent par le passé.

Peu à peu, les voix amérindiennes sont apparues dans les musées, tel que le Museum of Indian Arts \& Culture, et dans les parcs nationaux ; en 2013, Aztec Ruins a ainsi remplacé sa vidéo de présentation, autrefois centrée sur un discours uniquement scientifique, par une nouvelle projection focalisée sur la vision des Amérindiens affiliés à ce patrimoine, exposant tour à tour différents Indiens Pueblos et Navajos exprimant ce que ce patrimoine symbolise pour eux, un patrimoine non pas archéologique mais bel et bien vivant à leurs yeux, sacré puisqu'habité par l'esprit de leurs Ancêtres. 
« Dans nos histoires hopi de migration, Pueblo Bonito \{à Chaco\} et d'autres villages de la vallée étaient des lieux de repos pour beaucoup de clans avant leur dernier voyage vers les mesas. Ces clans ont des liens ancestraux avec cette zone [...]. Quand je visite cet endroit, je ressens \{son\} mystère et \{sa\} signification. Les Pueblos rendent encore un hommage spirituel à cette "empreinte" 21 car aucun site archéologique n'est considéré comme "abandonné”. Pueblo Bonito est encore un héritage vivant pour nous et pour d'autres Pueblos » (L. J. Kwwanwisiwma, Hopi ; Museum of Indian Arts \& Culture, Santa Fe - O'Donnell, 2001).

tribaux à préserver ces ressources placées sous leur égide; il s'agit de l'Indian Trust Responsability ${ }^{22}$. Nous verrons plus loin comment les différentes visions du patrimoine entre les tribus et le Gouvernement Fédéral affectent la gestion de ces sites. Il est intéressant d'ajouter que certains membres du National Park Service prennent à cœur cette responsabilité, parfois même à l'excès ; ainsi, les rapports des réunions entre les tribus et le Gouvernement Fédéral, qui ont commencé dans les années 1990, sont précieusement « protégés $»^{23}$.

\section{Un regard patrimonial différent, celui des « descendants »}

\section{Le poids de l'histoire - un passé qu'il faut « racheter »}

Autant à Chaco qu'à Mesa Verde, le poids du passé est fortement présent. La mise en patrimoine de ces parcs ne s'est pas faite sans conséquence mais parfois même à l'encontre d'Amérindiens qui vivaient là et qui en ont été expulsés. La directrice des ressources culturelles de Chaco l'avoue elle-même, ces populations sont pourtant celles qui ont su préserver ces sites pendant presque un millénaire (Int. D. Ford - 10/12) ; en terre tribale, les sites que nous croirions laissés à l'abandon, ont en réalité été protégés et gardés à distance par respect pour les esprits qui les habitent. Ces croyances ont donc conservé ces lieux de l'action de l'homme et certains restent remarquablement préservés. Mais à Chaco et Mesa Verde, lorsqu'il fut décidé de mettre en patrimoine ces parcs, le choix fut d'expulser les populations qui vivaient là depuis des centenaires, afin d'ouvrir ces terres à une communauté nationale et internationale ; ainsi, les terres de Mesa Verde ont été achetées aux Utes en échange d'autres terres et d'une rétribution monétaire. Ces derniers ressentent actuellement une forte injustice pensant que les 20000 \$ payés par le Gouvernement Fédéral pour ces terres correspondaient à un paiement annuel et non un versement unique (int. Cl. Spencer, Surintendant de Mesa Verde, 08/13). Le Parc National attirant presque 489000 visiteurs par an (National Park Service, 2012) contre seulement quelques milliers pour le Ute Mountain Tribal Park (int. guide Ute, Ute Mountain Tribal Park, 08/13), il est clair que les Utes peuvent éprouver une certaine amertume face à cette perte de revenus économiques. Cependant, ce dernier présente une offre très différente, n'attirant essentiellement qu'un public déjà connaisseur (ibid.), ayant déjà visité de nombreux autres patrimoines amérindiens de la région; en ne réalisant que deux tours par jour (l'un d'une demi-journée, l'autre d'une journée), l'accès est donc extrêmement réduit et contrôlé. De plus, l'expérience est bien 
plus centrée sur la culture amérindienne par la présence d'un guide autochtone; en prime, elle est plus appréciable pour certains du fait de la longueur des tours et de la taille des groupes, variant de 2 à 9 personnes seulement contre 30 à 60 au maximum à Mesa Verde.

A Chaco, le contexte est légèrement différent ; les familles navajos qui vivaient là, et ce probablement depuis le début du XVI ${ }^{\text {ème }}$ siècle (int. B. Chavarria, Santa Clara Pueblo, 09/13), ont été peu à peu déplacées à l'extérieur des limites fixées par le parc après la $2^{\text {nde }}$ Guerre Mondiale ; la dernière habitante de Chaco vivait à Casa Rinconada, l'un des sites majeurs ouvert aujourd'hui au public, dans un hogan traditionnel. En 1948, cette femme âgée fut la dernière à résister : " chaque jour, ils l'amenaient dans sa famille à plusieurs kilomètres de là et chaque fois, elle retournait chez elle à pied... jusqu'au jour où ils ont détruit son hogan et elle n'avait \{alors\} plus d'autres choix» (int. C. Winkler, 08/13, ranger à Chaco Canyon). Ces évènements ont marqué les esprits et soulignent cette forte évolution des mentalités du Gouvernement Fédéral et de ses employés; ce sentiment de culpabilité ressenti pour la façon dont les Amérindiens ont été traités à l'époque coloniale, et même plus tard comme nous venons de le voir, est omniprésent. Au-delà d'un aspect culturel et territorial, il s'agit aussi d'une affaire politique; les employés du National Park Service s'expriment d'ailleurs très prudemment dès qu'il s'agit d'aborder la question des Amérindiens. Il va sans dire que le Gouvernement éprouve depuis un besoin de se racheter, de réparer les torts causés à ces peuples autrefois dénigrés, en les intégrant aujourd'hui comme consultants de ces parcs nationaux mais aussi, en leur permettant de travailler coude à coude avec de nombreuses autres agences fédérales telles que le service des Eaux et Forêts, BLM (Bureau of Land Management) ou encore le Laboratoire National à Los Alamos (LANL), essentiellement dans la préservation des milliers de sites historiques (int. Bryan, San Idelfonso Pueblo, 09/13) présents sur ces terres.

\section{Navajos contre Pueblos. Un conflit territorial ancestral.}

40 A l'heure actuelle, le territoire reste toujours une forte source de conflit entre les différents groupes amérindiens peuplant le Nouveau-Mexique et le Colorado. Interrogés sur la question, les Pueblos sont souvent en désaccord avec leurs autres voisins pueblos concernant des parcelles de terrain; les principales raisons sont tout autant culturelles qu'en rapport avec ressources qu'elles possèdent. L'eau reste, surtout dans ces zones parfois très désertiques, un élément indispensable et donc disputé, à tel point qu'il n'est pas rare que certains déclarent une affiliation culturelle à certaines terres et aux « ruines » qu'elles abritent, afin de légitimer leur demande de restitution de terre. Ainsi, San Idelfonso a "récupéré » par décision du Gouvernement Fédéral sa Black Mesa, montagne sacrée autrefois partagée avec Santa Clara Pueblo, son voisin qui lui pourtant considère encore ces terres comme faisant partie de son territoire ancestral propre. De la même façon, San Juan revendique historiquement certaines terres, ressources en eau, à l'encontre de Santa Clara, aujourd'hui propriétaire de ces dernières. Ailleurs, les villages de Laguna et Acoma présentent ce même genre d'affrontements; une fois de plus, le Gouvernement Fédéral a joué un rôle de médiateur; resté neutre sur le sujet, il les a tous deux invités à utiliser une même parcelle. Des situations similaires ont lieu entre Hopis et Navajos, la réserve hopi étant incluse à l'intérieur de la seconde, bien plus étendue. 
41 Alors que les Pueblos arrivent à mettre de côté leurs différents pour présenter un front commun face au Gouvernement Fédéral en matière de patrimoine et rapatriement, cette rivalité historique entre Navajos et Pueblos, mais surtout Hopis, persiste fortement. La présence de la réserve navajo en terres ancestrales pueblos en est la raison; pour les Pueblos, les Navajos ne devraient pas revendiquer de filiation avec les Ancêtres Pueblos et leur héritage, comme ils l'ont fait pour Mesa Verde ou Chaco Canyon, sites qui pour eux sont uniquement le fruit du travail pueblo. Toujours selon eux, la seule légitimité à cette prétendue affiliation résulterait de mariages interculturels durant les siècles suivants, et non parce qu'ils y étaient à l'origine.

En général, ce discours s'accorde avec celui des archéologues dont beaucoup supportent l'idée que les Navajos seraient venus du Canada dans les années 1500 (int. B. Chavarria, 09/13). De toute évidence, il n'est pas si facile d'en avoir la certitude car ce n'est pas à l'échelle de la tribu mais du clan qu'il faut étudier cet aspect; certains clans, parmi les Hopis par exemple, revendiquent une descendance directe avec Chaco. De la même façon, certains clans navajos déclarent avoir été " participants ", d'autres avoir un lien direct avec ces lieux, « et certains l'ont ... mais encore une fois, nous mettons "ce cercle politique " autour d'eux en pensant parce qu'ils sont tous Navajos, ils doivent avoir la même opinion sur un endroit mais nous savons que ce n'est pas le cas » (Int. D. Ford - 10/12); si c'est ce qu'ils « nous assurent, c'est qu'ils sont affilié à ce lieu» (ibid.). De ce fait, le Gouvernement Fédéral, lors de l'application de NAGPRA, a préféré se focaliser sur les paroles rapportées par chaque tribu, et non pas sur ce que d'autres tribus pensaient d'elles (ibid.); c'est précisément pour cette raison que les Navajos, au désarroi des Pueblos (int. B. Chavarria, int. Bryan, 09/13), ont été pareillement ajoutés à la liste des tribus officiellement affiliées à Mesa Verde, Chaco Canyon et Aztec Ruins.

43 Cependant, cette décision n'a pas non plus fait l'unanimité parmi la communauté scientifique; anthropologues et archéologues ont grandement reproché au Parc l'approche méthodologique employée pour déterminer les affiliations culturelles. Ainsi, l'archéologue Linda Cordell est intervenue en tant qu'experte lors de la réunion de 1999 du NAGPRA Review Committe (NRC) à Silver Spring (Maryland); elle stipula clairement qu'aucune évidence de la présence navajo avant le XVI ${ }^{\mathrm{ème}}$ siècle n'avait été faite dans cette partie du pays. De la même façon, Dr Keith Kintigh de l'American Association of Physical Anthropologists (AAPA), ajouta que les évidences scientifiques et traditionnelles n'avaient pas été traitées de façon équilibrée. En réponse, deux membres de l'équipe du Parc qui avait constitué le dossier présenté au NRC, ont défendu leurs idées dans un article présentant leurs démarches; l'association des traditions orales données par chaque tribu et ce qu'ils appellent des "évidences biologiques " prouvent, selon eux, que de multiples tribus actuelles du Sud-Ouest, Navajos y compris, ont une affiliation avec les Chacoens (Schillaci, Bustard, 2010).

\section{Le regard porté sur leur propre culture, un savoir à l'échelle des clans}

Nous l'avons vu, certains clans ne ressentent pas toujours une connexion directe forte avec ces sites du Patrimoine Mondial, Chaco Culture et Mesa Verde, relativement éloignés des terres où leurs ancêtres ont choisi de s'établir à partir des années 1400 . Dans l'ensemble, les Pueblos installés le long du Rio Grande sont souvent plus attachés 
à un site historique que leurs ascendants ont habité plus récemment avant de trouver leur «terre promise ", lieux où ils ont établi leurs villages actuels; par exemple, Santa Clara reconnait des liens directs avec le site de Puye Cliff, très proche de leur village actuel, et San Idelfonso avec Tsankawi, portion du Parc National de Bandelier. Si leurs implications dans la gestion des sites de Mesa Verde et Chaco semblent limitées à des réunions essentiellement annuelles, leurs actions quotidiennes semblent beaucoup plus prononcées et nécessaires sur ces sites proches de leurs demeures actuelles et les milliers de sites qu'abritent leurs réserves. Leurs équipes tribales étant très réduites en culture et préservation, ils focalisent leur travail sur ces sites plus récents dont les histoires orales les concernant restent encore très précises.

Ainsi, Bryan de San Idelfonso (Int. Bryan, 08/13, Mesa Verde) admet que leur savoir sur des sites très anciens comme Chaco et Mesa Verde est très réduit par rapport à des sites géographiquement et historiquement plus proches comme Tsankawi. D'ailleurs, Chaco suscite encore de grandes interrogations quant à la raison de la création d'un tel endroit et de son utilité ; les différentes tribus pueblos émettent souvent des histoires divergentes et certains affichent même, à l'instar des scientifiques, plusieurs possibilités, allant d'un lieu d'apprentissage de la sorcellerie et de l'astrologie, à un lieu considéré comme une prison pour les Ancêtres Pueblos qui vivaient à proximité. Une chose est certaine, l'incertitude règne, même parmi les descendants des populations qui autrefois vivaient là ; cette confusion est sans doute liée au fait que l'histoire de chaque clan lui est propre et son savoir unique, savoir qui est ignoré du reste de la communauté, au sein d'un même village. Ce savoir n'est donc pas accessible à tous les membres tribaux, encore moins à une personne étrangère à la tribu.

Aussi, il arrive parfois que des Indiens Pueblos n'aient aucune idée de cette connexion existant entre eux et ces sites ou s'ils le savent, leur savoir se limite souvent à ce simple fait, ceci notamment au sein des jeunes générations qui finissent par se tourner vers les publications euro-américaines sur la question; cette perte de la transmission du savoir affecte la majorité de ces villages dont les traditions orales ne sont pas transmises à l'école; ce rôle, qui devrait toutefois incomber aux familles, est de moins en moins assumé par ces dernières. "Ça devrait se faire à l'ancienne, dans les kivas » mais ce temps est révolu (int. J. Aragon, Acoma, 09/13). Ainsi, le plus souvent, ce n'est que s'ils font une démarche personnelle qu'ils en apprennent plus sur leurs origines; ce visiteur de Laguna Pueblo (int. Chaco, 08/13) rapporte ainsi qu'il n'a « appris l'histoire du SudOuest \{à l'école\} que du point de vue des Blancs »; de plus, "personne dans \{son\} [...] village parmi les Aînés ne parle de ces sites »; curieux d'en savoir plus, il a alors décidé de se rendre auprès d'eux afin d'obtenir des réponses à ses interrogations. Cette démarche, il le reconnut, avait pour but de mettre en relief les deux différentes sources, l'une archéologique, l'autre issue des traditions orales, afin de visiter ces sites avec le regard de l'homme imprégné de sa culture ; son attitude, bien que très discrète, laissa transparaître une pointe d'ironie face à certaines hypothèses archéologiques évoquées par le ranger, et dévoilant de toute évidence qu'il pensait détenir les véritables réponses à ces interrogations, réponses qu'il garda toutefois secrètes; «ces discours archéologiques ne sont pas vraiment exacts ; les Blancs sont venus, ont fouillé, ont emporté tous les objets... et pensent avoir les réponses [...]. Je reconnais qu'ils ont assez de savoir et de techniques modernes pour émettre des hypothèses \{plausibles\}: nous, nous savons certaines choses grâce à nos traditions » (ibid.). 

histoires orales de leur clan les rattachent à d'autres lieux (int. Pueblo de Jemez, 09/13).

\section{Un regard porté à distance} regard distant, par crainte et par respect pour les esprits qui reposent en ces lieux. Ils ne voient donc pas ces «ruines » de la même façon que les Euro-Américains qui les visitent en tant que sites archéologiques, considérés par beaucoup comme les témoignages d'une culture passée, disparue. Aussi, à Mesa Verde notamment, les visiteurs amérindiens ne constituent qu'une infime partie du tourisme global du lieu en question, soit $1 \%$, contre $94 \%$ de visiteurs blancs (Mesa Verde NPS Study, 2012). Ceci semble aussi être le cas à Aztec Ruins et Chaco Canyon; sur une centaine de visiteurs rencontrés là-bas, seulement sept étaient d'origine amérindienne, dont uniquement deux d'origine pueblo. Ces sites restent donc très peu fréquentés par les descendants des Ancêtres Pueblos; arpenter ces endroits sacrés reste aussi tabou pour les Navajos, qui essayent dans le meilleur des cas de garder leur distance ; il est souvent mal vu des familles de travailler dans de tels lieux, comme c'est le cas de plusieurs Navajos à Chaco Canyon et Aztec Ruins. Dans ce dernier, les deux membres de la Navajo Nation travaillant pour le National Park Service reconnaissent s'y rendre le moins possible, uniquement par nécessité professionnelle (int. K. Murphy \& Terri, Aztec Ruins, 07/13).

A Chaco, H. Suina, Medecine Man de la tribu des Cochiti et restaurateur archéologique, révèle que leur rapport à ces sites dépend de leurs croyances; pour lui et d'autres parmi les Pueblos, ainsi que parmi les Navajos aussi (int. T. Begay, Navajo, 10/12 ; int. Fl. Vallo, Acoma Pueblo, 07/13), «si nous venons sur ces lieux avec de bonnes intentions, rien ne nous arrivera; c'est si nous venons avec une pensée négative, comme avec l'idée de prendre quelque chose du lieu, que nous pouvons en être affecté \{et perdre notre équilibre interne\}» (int. Harold Suini, Chaco, 07/13). C'est pourquoi, tous les matins, avant de commencer la restauration de ces sites sacrés, ce dernier prend quelques minutes pour prier, avertissant les esprits de ses intentions et sollicitant l'aide nécessaire à accomplir un travail honorable (ibid.). La visite de ces sites ne se fait donc pas sans intention particulière, ou sans une préparation au préalable ; il ne s'agit pas de tourisme à proprement parler, plutôt d'un pèlerinage, un retour aux racines, un support à leur apprentissage culturel et à l'exploitation des ressources. Ainsi, la visite de Chaco est souvent incluse dans le programme éducatif des écoles environnantes navajos (int. Chr. Czazasty, Chef de l'équipe d'interprétation de Chaco, 10/12).

51 En parallèle, les Amérindiens visitent aussi ces sites en groupe ou en famille, afin de transmettre leur savoir à leur descendance ; à l'exception de très rares exemples, ils ne ressentent pas la nécessité de suivre les visites guidées ou de lire les guides papier (observation de terrain). C'est de façon libre et privée qu'ils veulent parcourir ces paysages culturels. 

peuplent leurs terres tribales; de ce fait, les sites historiques contenus dans les réserves de Santa Clara et San Idelfonso, par exemple, ne sont accessibles qu'aux membres tribaux, à l'exception du parc de Puye Cliff. Leur influence se fait aussi ressentir sur les terres voisines sous l'égide du Gouvernement Fédéral avec qui ils travaillent en partenariat; le bureau de préservation de Santa Clara a ainsi poussé le Laboratoire National de Los Alamos à clôturer une partie des terres après le grand incendie qui a frappé la zone en 2011 (int. Bryan, 09/13). Pour les Pueblos, la véritable raison est d'une part de faire face au nombre croissant de pillages; certains sites comme la Cave Kiva (Mortendad Canyon), ouverts au public mais sans surveillance faute de moyens, ont fini par être totalement fermés à cause de l'irrespect porté à ces lieux par certains visiteurs ; d'autre part, il s'agit de garder ces lieux protégés de la curiosité excessive de personnes étrangères à ces tribus afin de pouvoir y réaliser de façon privée leurs cérémonies et activités coutumières. Certains le reconnaissent, s'ils pouvaient hypothétiquement récupérer ces Parcs Nationaux, ils les fermeraient probablement au public afin de les préserver (int. B. Chavarria, 09/13). Mais ils savent pertinemment qu'une telle restitution les diviseraient entre eux d'un point de vue foncier, à tel point que la gestion par un organisme «neutre » est perçue comme nécessaire et par ailleurs satisfaisante car elle répond à la curiosité que les cultures étrangères portent sur leur propre culture tout en les gardant à distance de leurs lieux de vie (ibid.).

conséquent, ces Amérindiens supportent le tourisme dans les Parcs Nationaux tout en considérant que ceux-ci suffisent à satisfaire la curiosité culturelle des visiteurs, ne désirant pas attirer ce même nombre d'individus sur leurs terres privées, à l'exception de Taos et Acoma Pueblo, les seuls à avoir vraiment développé une "culture accueillante ». Pour le Lieutenant-Gouverneur d'Acoma (int. J. Aragon, 09/13), ils se doivent de permettre au public de faire la connexion entre ces sites anciens et les populations qui habitent les villages actuels. Contrairement aux croyances d'une grande partie des visiteurs de ces Parcs Nationaux, appuyées par le fait qu'ils ne sont qu'un très faible pourcentage à visiter des pueblos en parallèle (moins de $1 \%$ à Mesa Verde) ${ }^{24}$, ces sites sont les témoignages d'une culture belle et bien vivante; "peu importe que vous parliez d'Acoma en bien ou en mal, l'essentiel, c'est d'en parler »; la population s'élevant à moins de 4000 habitants, le tourisme est alors encouragé pour faire des visiteurs les ambassadeurs de leur existence (ibid.).

Enfin, ce regard est également divisé de la même façon en matière de préservation; tout élément doit suivre un cycle naturel; émergeant de la terre, il est destiné à retourner à la terre. Ce concept est loin de correspondre aux critères de préservation $\mathrm{du}$ patrimoine appliqués par les conservateurs du patrimoine, soutenus par la convention de l'UNESCO. Ce débat réapparaît constamment lors des réunions tribales du National Park Service. Certains Amérindiens invitent les archéologues à cette réflexion : la chute d'un mur a-t-elle une quelconque conséquence sur la valeur portée au lieu? (Th. Pasqual, Acoma Pueblo, réunion tribale de Mesa Verde, 08/13). De toute évidence, leurs cultures accordent plus de valeur à un paysage culturel qu'aux propriétés physiques d'un bâtiment. 


\section{Conclusion : Un regard évolutif, approbateur dans le contexte de la mondialisation}

La création de NAGPRA ne représente que la dernière étape d'une longue "bataille " menée par les Amérindiens, connue sous le nom de Repatriation Movement, développé entre les années 1880 et 1970 . Ce n'est qu'un siècle après le début de ce mouvement que va vraiment apparaitre cet éveil relatif à la façon dont les restes humains et objets culturels des Amérindiens étaient traités et exposés dans les musées (Fine-Dare, 2002). Ainsi, Esther, femme momifiée qui constituait l'une des grandes attractions du parc de Mesa Verde, fut finalement retirée de la vue du public à la fin des années 1980 et restituée à ses descendants, après 40 ans d'exposition en vitrine. De la même façon, la Grande Kiva de Casa Rinconada, jusque-là accessible à tous, fut définitivement fermée en 1996, officiellement pour des raisons de préservation; en arrière-scène, les Amérindiens avaient, outre des inquiétudes relatives à la préservation du lieu, exprimé un mécontentement face au nombre croissant de pratiques New Age depuis 1991, consistant en dépôts non autorisés d'offrandes et de crémation. Le fond du débat était basé sur la véritable légitimité de certains visiteurs à utiliser la kiva pour leurs propres croyances et ainsi violer ou s'approprier le caractère sacré de « leur » lieu (De la Torre et al., 2003). Au final, certains Amérindiens ressentirent que cette décision, qui aurait dû conduire non pas à une totale fermeture mais à une sélection des visiteurs, avait été l'acte de "groupes qui n'avaient pas de revendication culturelle par rapport au lieu " (ibid.). En effet, la raison officielle divulguée fut celle de protéger les ressources physiques; en aucun cas ne fut abordée la question religieuse lors du processus de décision, et ce, très probablement pour des raisons politiques, afin d'éviter d'aborder publiquement la question des discriminations religieuses. Interrogés aujourd'hui, les membres du Parc de Chaco diront pourtant que cet endroit a été fermé par respect pour les descendants de ces populations. Ces actes, à Mesa Verde, Chaco et même Aztec Ruins, où les ossements humains ont été retirés du musée depuis les années 1990, attestent d'une progression lente mais certaine du respect accordé aux Amérindiens affiliés et à leurs traditions, aujourd'hui désormais consultés et écoutés; nous l'avons vu, leur parole revêt aussi une valeur scientifique quand il s'agit de parler d'objets issus de leur propre culture. Même en matière de management, le Surintendant de Mesa Verde reconnaît qu'ils peuvent être de très bon conseil ; certains Pueblos se sont par exemple beaucoup impliqués dans le projet du nouveau centre d'accueil du site (int. Br. Spencer, Mesa Verde, 09/13 ; int. P. M Pino, Zia Pueblo, Mesa Verde, 09/13) ; très fiers de ce partenariat et de ce qu'il en a résulté, ces derniers ont tenu à être photographiés à l'entrée, près de la plaque nommant les tribus affiliées et leur travail. Il est donc indéniable que les relations entre les tribus et les membres du Gouvernement Fédéral, et même entre les tribus issues de cultures différentes, a largement évolué ces vingt dernières années; T. Begay et d'autres n'ont pas manqué de signaler qu'aujourd'hui, même si les choses avancent lentement et même si certains désaccords persistent lors de ces réunions tribales avec le National Park Service, ils arrivent enfin à discuter calmement, sans élever la voix entre eux: "à une époque on se criait dessus! Maintenant, nous sommes pris en considération. Mais au lieu d'écrire des lois et nous consulter après, on devrait nous consulter pour les écrire» (int. T. Begay, Aztec, 07/13) ; le fait que certains membres se connaissent depuis des années n'est pas anodin non plus. Il s'est instauré une relation de confiance et de respect, voire aussi d'amitié 
entre la plupart d'entre eux. Néanmoins, cette évolution n'est pas le seul fruit de cette entente, loin de là. Bien que certains défendent toujours leurs valeurs traditionnelles et donc s'opposent au travail de restauration effectué par le service des parcs concernés, la plupart reconnaissent avoir réalisé que la nouvelle génération est plus proche de la vision euro-américaine; ces représentants de tribus, parents et grands-parents, découvrent que la majorité de leur descendance préfère ne plus apprendre la culture amérindienne par les voies traditionnelles, apprentissage qui demande l'investissement d'une vie ${ }^{25}$. Au lieu de se connecter à ces sites anciens grâce aux traditions orales et spirituellement par le biais de rituels, la découverte de ce patrimoine par les dernières générations se fait donc de la même façon que pour les Euro-Américains, à travers les livres et l'archéologie. A l'heure actuelle, les représentants de ces cultures auprès des parcs se résignent donc de plus en plus à opter en faveur d'une conservation du patrimoine, afin que leurs descendants puissent le visiter; ainsi pour eux aussi, il devient donc nécessaire de préserver les propriétés physiques des monuments qui vont servir à préserver la transmission de leur savoir et de leur culture, s'alignant ainsi sur l'une des missions de la Convention de l'UNESCO engageant les États parties à «la protection, la conservation, la mise en valeur et la transmission aux générations futures du patrimoine culturel et naturel» (UNESCO, 1974). Ces sites, témoignages physiques de leurs histoires migratoires, détiennent la clef de leur origine sur cette terre - le savoir de leur provenance étant indispensable à leur survie-, et légitiment leur présence sur ce territoire.

C'est donc cette évolution des mentalités parmi les Amérindiens, dans le contexte de la mondialisation, accompagnée de l'évolution des regards envers la culture amérindienne, du côté des Euro-Américains gouvernant ces sites, qui a permis une évolution des relations interculturelles à l'échelle patrimoniale.

Enfin, à l'échelle nationale et mondiale, ce progrès est plus lent, notamment par ignorance de l'autre culture, soutenue par un imaginaire qui s'étend bien au-delà du territoire patrimonial ; aussi, les tribus concernées montrent un désir de renverser la situation du siècle dernier au cours duquel les ethnologues «blancs" avaient plein pouvoir sur la diffusion de cette culture qui leur était étrangère. Par conséquent, ils prennent de plus en plus les rênes concernant la gestion de leur patrimoine, en tant que consultants, guides touristiques, restaurateurs... Ils restent cependant peu nombreux et leur travail, dans l'ombre, n'est que peu connu du public. Qui sait par exemple que les guides papier de Bandelier National Park ont été révisés par un membre de la tribu voisine au parc, San Idelfonso ? Aussi, de façon générale, c'est par l'expression de leur art, lors de manifestations culturelles sur les sites ou dans les musées, qu'ils ont le plus de contacts directs avec les visiteurs et peuvent partager un peu de leur culture. Leur présence de plus en plus marquée en ville et dans les écoles publiques se révèle être un facteur important; dans les villes du Nouveau-Mexique et Colorado comme Durango, Farmington, Albuquerque..., où leur présence est fortement ressentie physiquement et par l'intermédiaire de lieux patrimoniaux dédiés à ces populations, leur culture est connue, souvent appréciée. Dans cette optique, la ville de Taos soutient pleinement les activités de Taos Pueblo, village voisin de la tribu amérindienne dont elle porte le nom; de nombreuses relations d'amitié se sont développées entre ces populations de diverses cultures (int. Al. Naranjo, Southern Ute Tribe, 09/13) ; aussi, leur fête annuelle est-elle un évènement très prisé et apprécié des habitants de cette ville voisine qui ne manquent pas d'y participer. 
Pour finir, les regards envers ces cultures sont donc plus riches et plus ouverts, car accompagnés d'une (re)définition de la culture amérindienne et de la « réécriture » de leur Histoire et par conséquent, d'une meilleure compréhension de "l'autre » culture. D'ailleurs, il a pu être remarqué que ces Amérindiens, représentants de leur tribu auprès du Gouvernement Fédéral, ont tendance à être très ouverts aux académiciens, d'autant plus s'ils sont étrangers ; ils sont désireux de faire découvrir leur culture sans intermédiaire, directement "d'un Amérindien ", et par la même occasion, de rectifier ces clichés qui les incombent. "Certains aînés disent que ça ne vous regarde pas, que vous n'avez pas besoin de savoir; je pense le contraire (...). Je ne vous ai pas tout dit, c'est sûr, mais je vous ai dit ce que vous deviez savoir " (int. Bryan, 09/13). Et ce partage, cette transmission culturelle qui atteste de leur existence, elle ne peut se faire, de par leur tradition, par écrit ; c'est pour cette raison qu'ils se rendent aux réunions du Gouvernement, afin de témoigner par la parole de leur existence (int. J. Aragon, 09/13). Ainsi, cet échange s'opère de la même façon qu'aux temps de leurs Ancêtres Pueblos, de la façon dont leurs peuples ont continué à le faire pendant des millénaires, par le biais de la parole, et par le regard, le regard d'un être vivant sur son semblable, le regard d'une culture sur une autre, un regard présent, profond, défensif de ses valeurs, approbateur, compréhensif, évolutif, désireux d'apprendre ou de partager... un regard plein d'admiration.

\section{BIBLIOGRAPHIE}

CLASSEN C. (1998), The Color of Angels : Cosmology, Gender and the Aesthetic Imagination, New York, Routledge.

COUSIN S. (2008), « L'Unesco et la doctrine du tourisme culturel », Civilisations, 57, 1-2, Bruxelles, Institut de sociologie de l’Université Libre de Bruxelles, pp. 41-56.

COUSIN S., MARTINEAU J.-L. (2009), « Le festival, le bois sacré et l'Unesco. Logiques politiques du tourisme culturel à Osogbo (Nigeria) », Cahiers d'Etudes Africaines, 194, Paris, Editions de l'E.H.E.S.S., pp. 337-364.

DE LA TORRE M., MAC LEAN M., MYERS D. (2003), Chaco Culture National Historical Park, U.S. National Park Service, A Case Study, Los Angeles, The Getty Conservation Institute.

FINE-DARE K. S. (2002), Grave Injustice: The American Indian Repatriation Movement and NAGPRA, Nebraska, University of Nebraska Press.

GARRAIT-BOURRIER A., VÉNUAT M. (2002), Les Indiens aux États-Unis : renaissance d'une culture, Paris, Editions Ellipses.

HEINICH N. (2009), La fabrique du patrimoine. De la cathédrale à la petite cuillère, Paris, Maison des Sciences de l'Homme.

HEINICH N. (2010), « La construction d'un regard collectif : le cas de l'Inventaire du patrimoine », Gradhiva, 11, Paris, Musée du Quai Branly, pp. 162-180. 
NATIONAL PARK SERVICE (2012), “Annual Park Ranking Report (1979 - Last Calendar Year)”, IRMA, https://irma.nps.gov/Stats/SSRSReports/National \%20Reports/Annual \%20Park \%20 Ranking \%20Report \%20(1979 \%20- \%20Last \%20Calendar \%20Year , consulté le 23/10/13.

O'DONNELL J. K. (éd.) (2001), Here, Now, and Always : Voices of the First Peoples of the Southwest, Santa Fe, Museum of New Mexico Press.

PEREZ P. (2003), «L'enjeu des ruines en pays pueblo (Arizona et Nouveau Mexique, Etats Unis) », in GRAVARI-BARBAS M., GUICHARD-ANGUIS S. (dir.), Regards Croisés sur le patrimoine à l'aube du XXİ̀me siècle, Paris, Presses universitaires de Paris-Sorbonne, pp. 191-203.

PEREZ P. (2011), « Les enjeux identitaires autour de l'adobe dans le Sud-Ouest des Etats-Unis », in DE CHAZELLES C.-A. et al. (dir.), Les cultures constructives de la brique de terre, Editions de l'Espérou.

PICARD M. (1992), Bali. Tourisme culturel et culture touristique, Paris, L'Harmattan.

PICHOURON P. (2010), « Le Patrimoine architectural est affaire de regard », Patrimoine d'Argoat, http://patrimoinedargoat.free.fr/paysguingampais/html/introduction.html, consulté le 22/05/2013.

PUTNAM J. (2005), Report and Nomination Form, World Heritage Listing, Taos Pueblo, New Mexico, 2005. Disponible sur http://www.nps.gov/oia/topics/taos.pdf, consulté le 25/10/2013.

SCHILLACI M., BUSTARD, W. (2010), “Controversy and Conflict : NAGPRA and the Role of Biological Anthropology in Determining Cultural Affiliation”, PoLAR Political and Legal Anthropology Review, 33, 2, pp. 352-373.

SHIELDHOUSE R. (2012), “Two World Heritage Sites ; One Fortified Border Visitor Experience, Management and Outstanding Universal Values at Two Pre-Columbian Sites on Both Sides of a Fortified Border", lors du Colloque international Routes touristiques et itinéraires culturels, entre mémoire et développement, Québec, Canada, 13-15 juin 2012.

UNESCO (1972), Convention concernant la protection du Patrimoine Mondial culturel et naturel. Adoptée par la Conférence générale à sa dix-septième session, Paris. Disponible sur http://whc.unesco.org/ archive/convention-fr.pdf, consulté le 10/11/2013.

URRY J. (2001), “Globalizing the Tourist Gaze”, Cityscapes Conference, Graz, novembre 2001, université de Lancaster. Disponible sur http://www.humanitiesinstitute.buffalo.edu/docs/urryglobalising-the-tourist-gaze-1.pdf

URRY J. (2002), The Tourist Gaze, $2^{\mathrm{e}}$ édition, Londres, SAGE Publications.

VESCHAMBRE V. (2005) « Le recyclage urbain, entre démolition et patrimonialisation : enjeux d'appropriation symbolique de l'espace », Norois, 195/2005/2, mis en ligne le 08 août 2008. Disponible sur http://norois.revues.org/548, consulté le 15/11/2013.

\section{NOTES}

1. Le cas de Taos Pueblo, de par la particularité de sa gestion tribale et donc autonome, ne sera que partiellement abordé dans cette étude car il mérite un sujet à part entière et l'accent a été mis sur le travail du Gouvernement Fédéral avec les tribus affiliées.

2. Mesa Verde (classé en 1978 sur la liste du Patrimoine Mondial) http://whc.unesco.org/fr/list/ 27 - la culture Chaco (classé en 1978) http://whc.unesco.org/fr/list/353 et Pueblo de Taos (classé en 1992) http://whc.unesco.org/fr/list/492

3. Aujourd'hui, par respect pour les Indiens Pueblos, le terme navajo d'« Anasazi », qu'ils traduisent souvent par «Anciens ennemis », est remplacé par «Ancêtres Pueblos ». Certains 
Navajos diront au contraire qu'il signifie « Les Anciens Ancêtres » (int. H. Smith, Navajo Nation, Canyon de Canyon de Chelly, 09/13).

4. Native American Graves Protection and Repatriation Act. Pour plus de détails, voir Fine-Dare, 2002. 5. Les Utes ont également été ajoutés à la liste des descendants officiels. Cependant, ils reconnaissent dans l'ensemble avoir vécu dans la région au même moment mais attribuent les éléments architecturaux aux Pueblos (réunion tribale entre le National Park Service et Aztec Ruins, juillet 2013 - intervention de L. W Hartman, de la tribu des Ute Mountain). Le cas des Navajos, nous le verrons, est différent.

6. Le National Park Service n'autorise pas la réalisation et distribution d'interviews ou très difficilement après enquête et validation ou refus de certaines questions, ce qui représente un délai très important (6 à 9 mois). Les organismes responsables sont l'OMB (Office of Management and Budget) et le Département de l'Intérieur. Mais au jour d'aujourd'hui (10/13), les soumissions ne sont plus acceptées. Les universités ayant essayé de faire des enquêtes dans ces parcs ont dû se rabattre sur des questionnaires qui avaient été approuvés par le passé, dont les questions restent focalisées sur l'expérience et la satisfaction touristiques et non sur le savoir porté à ces cultures représentées par ces patrimoines.

7. Certains considèrent en effet qu'enregistrer leur voix, tout comme prendre leur portrait, peut capturer une partie de leur essence.

8. Certaines tribus font d'ailleurs le choix d'abandonner leur nom espagnol pour retrouver leur nom d'origine ; San Juan Pueblo, par exemple, s'appelle désormais Ohkay Owingeh.

9. Célèbre photographe américain dont les œuvres, atemporelles, ont traversé le temps sans vieillir. "L'Europe et l'Amérique elle-même, connurent un regain de passion pour les photographies de Curtis dans les années 1970 et 1980, avec expositions, impressions de cartes postales et de calendriers. Ce que véhiculent ces témoignages visuels est probablement commun à tous les êtres humains : la quête de sens, la conscience de l'éphémère et le besoin de partager l'authentique » (Garrait-Bourrier, Vénuat, 2002).

10. Le hogan était la maison traditionnelle des Navajos, construite circulairement, d'adobe et de bois, dont l'entrée était placée à l'est ; elle servait aussi de lieu cérémoniel. Aujourd'hui encore, ces structures reflètent le paysage culturel navajo.

11. Beaucoup d'Amérindiens reprochent aux Euro-Américains de ne rien savoir de leur culture et de leur histoire, "contrairement aux Européens » (cas des Français et des Allemands cités, les deux plus importants publics étrangers sur ces territoires; int. Joe Aragon, Acoma Pueblo, réunion tribale à Mesa Verde, 09/13).

12. 1924 : Indian Citizenship Act : attribution de la citoyenneté américaine aux Amérindiens.

13. Ces luttes se concentrent essentiellement sur le dédommagement des terres qui leur ont été confisquées et le rapatriement des restes humains et objets funéraires de leurs ancêtres sur les lieux originels de sépulture, enlevés au nom de la science et conservés depuis dans des institutions muséales (programme NAGPRA).

14. En effet, ce site, contrairement à Mesa Verde et Aztec Ruins, a la particularité de présenter un large public qui revient plusieurs fois; ce public se rencontre en été mais surtout en automne, période qui attire un grand nombre de retraités passionnés par ces patrimoines et ces cultures (int. D. Ford, Chef des Ressources Culturelles de Chaco, 09/12 et autres interviews auprès de touristes).

15. Ces affirmations résultent des enquêtes publiques réalisées par ces Parcs Nationaux mais surtout d'entretiens personnels menés auprès des équipes de gestion et des touristes.

16. Depuis ces quarante dernières années, ce dernier note cependant une large évolution de la présence des Amérindiens en ville, donnant l'exemple de sa ville natale, Durango (Colorado).

17. Par exemple, certains membres permanents de l'équipe d'Aztec Ruins ont ainsi pu, lors d'une réunion organisée avec certains représentants amérindiens, échanger des informations sur ces sites, ou plutôt prendre note de leurs propres interprétations en tant que descendants de ces 
sites. Ceci se reflète parfaitement dans leur discours de guide (int. ranger Sh. Montanari, Aztec Ruins, 07/13). Par contre, les parcs tournent plus de la moitié de l'année grâce à des volontaires et ces derniers ne reçoivent ni de formation, ni de recommandation particulière (int. L. Blacik, chef d'Interprétation d'Aztec Ruins, 08/13); en général, ces derniers, beaucoup moins expérimentés sauf s'ils ont renouvelé l'expérience plusieurs années, présentent un discours beaucoup moins «vivant ", soutenu par les recherches archéologiques, sans forcément réussir à connecter le public avec une culture encore vivante.

18. Une kiva avait et a toujours une utilisation à la fois cérémonielle et sociale, servant de lieu de rassemblement. Les Grandes Kivas, à la différence des kivas de clans, servent à abriter toute la communauté.

19. Il est cependant de plus en plus rare de voir une kiva circulaire dans les villages actuels, beaucoup affichant des kivas rectangulaires. L'un des rares exemples est celui de San Idelfonso, village dont la kiva circulaire, kiva la plus ancienne du village, est de nos jours appareillée avec deux kivas supplémentaires, carrées. Cette dernière est, de plus, bien plus rarement utilisée, probablement une seule fois par an. Sur la place centrale du village, elle reste par contre extrêmement bien entretenue.

20. D'après le recensement de 2010 , seulement $40,5 \%$ de la population est d'origine blanche, d'origine non hispanique. Avec 9,4\% d'Amérindiens, cet Etat est le second Etat le plus peuplé par ce groupe ethnique, après l'Alaska. Source : www.census.org

21. Les Pueblos, quand ils abordent l'histoire de leur migration, parlent d'« empreintes dans le paysage » (Landscape footprints).

22. Définition donnée dans Seminole Nation v. United States, 1942 ; plus de précision sur le site officiel du Bureau of Indian Affairs. Lien : http://www.bia.gov/FAQs/index.htm

23. Alors que j'ai pu en obtenir quelques-uns pour Aztec Ruins après sélection, et qu'il m'a été donné de participer aux réunions annuelles de Mesa Verde et Aztec Ruins avec les tribus, il m'a été impossible de regrouper ceux de Chaco Canyon, conservés à l'université d'Albuquerque ; pour ce dernier, il a fallu faire face à beaucoup de suspicion quant à mon travail et la façon dont seraient utilisées ces données et malgré tous mes efforts, mon déplacement là-bas s'est avéré inutile. Aussi, il est difficile d'interpréter l'attitude de ce membre du National Park Service, à savoir si elle voulait vraiment protéger les dires des Amérindiens ou au contraire, la « réputation » du Gouvernement Fédéral. Ailleurs, notamment à Aztec Ruins, ils se sont montrés beaucoup plus ouverts à ma démarche de chercheuse. Toutefois, ces rapports devraient être publics car ils rapportent les points de vue des Amérindiens sur les questions de patrimoine, ce qui reste trop rarement accessible ou mis en avant. Par ailleurs, si à un quelconque moment de la réunion, ces derniers désireraient que les notes soient interrompues pour garder un discours " privé », ils sont en droit de le faire. En conséquence, les rapports ne présentent aucun préjudice à leur égard.

24. Ceci est le résultat de ma propre enquête auprès des touristes et du Mesa Verde National Park Visitor Study (2012 - seulement 4 visiteurs de Mesa Verde sur 453 ont visité des Pueblos dont quatre Taos). En parallèle, il reste difficile d'avoir des chiffres de fréquentation pour Taos Pueblo; sur l'un des rapports réalisé par le Gouvernement Tribal et le National Park Service, le nombre de visiteurs indiqué est celui de 180000 par an, chiffre obtenu par la Chambre des Commerces de la ville de Taos (en indiquant que ça a chuté après septembre 2001 - Putman, 2005). Sur place, leur office de tourisme n'a pas su me fournir de documents sur la fréquentation touristique et ce chiffre semble loin de la réalité.

25. Cette perte est aussi marquée par un problème récurrent, celui de la langue ; toutes les tribus rencontrent ce problème actuellement. En effet, peu de membres parlent couramment leur langue native, souvent car ce travail n'est pas accompli au sein des familles. Pourtant, la langue est considérée comme un marqueur d'identité indispensable à la survie de leur culture. A Santa Clara, un seul adolescent parle couramment le Tewa ; « tous les Pueblos rencontrent ce problème 
[...] C'est triste, faut-il en venir à le rendre obligatoire \{apprentissage du Tewa\} pour sauver la culture?» (int. B. Chavarria, 09/13). Afin de faire face à la disparition de ce savoir, ils développent des formations linguistiques et culturelles ; à San Idelfonso, des stages d'été sont mis en place au cours desquels tous les enfants suivent 2 heures de langue par jour, le reste du temps étant dédié à des visites et cours culturels (int. Bryan, 09/13).

\section{RÉSUMÉS}

Cet article aborde le regard porté sur des cultures minoritaires, celles des tribus pueblos et navajos, à travers le patrimoine auquel elles sont culturellement affiliées. Les sites amérindiens inscrits au Patrimoine Mondial, Chaco Culture (Chaco Cañon et Aztec Ruins), Mesa Verde et Taos Pueblos (V ${ }^{\text {ème-XIVème }} \mathrm{s}$.) ont ainsi la particularité d'être rattachés à des cultures vivantes, dont les représentants ont gardé la mémoire des lieux animés par la présence de leurs ancêtres, à travers leurs traditions orales. À ce titre, par l'application de la loi NAGPRA, ces patrimoines, classés aussi en tant que Parcs Nationaux, à l'exception de Taos Pueblo, ont par conséquent été officiellement affiliés à des tribus actuelles vivant dans la région des Four-Corners (Utah, Colorado, Nouveau-Mexique et Arizona) ; ces États, habités par des populations qui ne se sont que peu déplacées depuis plus d'un millénaire, dont les vestiges et traditions légitiment leur appartenance à ces territoires, doivent faire face à de multiples enjeux qui s'étendent bien audelà du simple phénomène économique auquel le tourisme est toujours associé. Aborder les regards patrimoniaux des Euro-Américains portés sur la culture pueblo et navajo et ceux que les descendants des Ancêtres Pueblos portent sur leur propre patrimoine a ainsi pour but de mettre en relief les multiples dimensions de cette mise en patrimoine, autant à l'échelle locale que nationale ou mondiale. Dans le contexte actuel de la mondialisation, il semblerait que l'évolution des regards associés au patrimonial amérindien soit accompagnée d'une évolution des relations interculturelles sur le territoire patrimonial étendu.

Cette étude se concentre sur différents acteurs euro-américains, touristes ou professionnels associés à ces sites patrimoniaux, mais aussi sur les Amérindiens pueblos et navajos et le regard « différent » qu'ils portent sur leur propre patrimoine. Par la même, il s'agit de comprendre en quoi le patrimoine et les imaginaires tout comme les représentations qui lui sont associées peuvent interférer sur une culture, en permettant ou non sa revitalisation culturelle et la « réécriture » de son histoire.

This article approaches the gaze focused on minority cultures, the Pueblos and Navajos tribes, through their associated heritage. The Native American sites inscribed on the World Heritage List, Chaco Culture (Chaco Canyon and Aztec Ruins), Mesa Verde and Taos Pueblo ( $\mathrm{V}^{\text {th }}-\mathrm{XIV} \mathrm{V}^{\text {th }} \mathrm{c}$.) have the distinction of being linked to living cultures, whose representatives have kept memory of the places enlivened by the presence of their ancestors, through oral traditions. As such, with the implementation of the NAGPRA law, these heritage, also classified as National Parks, with the exception of Taos Pueblo, were therefore officially affiliated with existing tribes living in the Four Corners region (Utah, Colorado, New Mexico and Arizona). These states are inhabited by populations who have rarely migrated in more than a millennium, whose numerous culturally affiliated remains and oral traditions legitimize their belonging to these territories; they are in consequence faced with multiple issues that extend far beyond the simple economic phenomenon more often than not associated with tourism. Thereby, dealing with the Anglo- 
American's heritage gazes on these cultures, pueblo and Navajo, aims to highlight the multiple dimensions of this heritage development, at every scale. In the current context of globalization, it seems that the evolution of the gazes associated to Native American heritage is accompanied by an evolution of intercultural relations in the extended heritage territory.

This study focuses on Anglo-American actors, tourists and professionals associated with these heritage sites, as well as on the Pueblo and Navajo Indians and the "different" gaze they have of their own heritage. Additionally, it aims to understand how the heritage and the imaginary associated with it can interfere with a culture, allowing or not its cultural revitalization and the "rewriting" of its history.

\section{INDEX}

Mots-clés : regard patrimonial, cultures minoritaires, revitalisation culturelle, dynamiques territoriales, Indiens Pueblos, Navajos, Patrimoine Mondial, imaginaires géographiques, gestion du patrimoine, Mesa Verde, la culture Chaco, tourisme

Keywords : heritage gaze, minority cultures, cultural revitalization, territorial dynamics, Indian Pueblos, Navajos, World Heritage, geographical imaginary, heritage management, Mesa Verde, Chaco culture, tourism

\section{AUTEUR}

\section{ESTELLE BRUN}

Paris 1 Panthéon-Sorbonne, estelle.brun@gmal.com 